Joint Institute for High Temperatures, Russian Academy of Sciences

(Izhorskaya Str. 13, Moscow 125412, Russia; e-mail: aemelia@ihed.ras.ru)

\title{
EXPERIMENTAL AND THEORETICAL STUDY \\ OF CHARGING OF CARBON NANOPARTICLES IN SHOCK-HEATED PLASMA DURING PYROLYSIS PACS 36.40.Wa, 34.70.+e OF CARBON-CONTAINING MOLECULES
}

\begin{abstract}
This work is devoted to the experimental and theoretical study of charged carbon nanoparticles formed at the pyrolysis of various carbon-containing substances behind shock waves. The experimental results and the computer simulation of the electrical charging of carbon nanoparticles produced during the pyrolysis of $\mathrm{C}_{3} \mathrm{O}_{2}, \mathrm{CCl}_{4}$, and $\mathrm{C}_{6} \mathrm{H}_{6}$ in shock waves are presented. The measurements of the nanoparticle charge by electric probes, as well as their temperature by emission-absorption spectroscopy and size by LII, were performed simultaneously. The results of simulation show a satisfactory agreement with the experimental data.

Ke ywords: shock-wave pyrolysis, carbon particle formation, charging of nanoparticles, kinetic model of the charging of carbon nanoparticles.
\end{abstract}

\section{Introduction}

This work continues the series of investigations of the kinetics of formation of carbon particles during the shock-wave pyrolysis of various carbon-bearing species [1-7]. Investigations of complex plasma-particle systems, which have been actively studied during the last years [8-10], were quite helpful and gave information for a qualitative analysis of the observed data. In $[5,6]$, we studied the charging process of nanoparticles formed upon the decomposition of $\mathrm{C}_{3} \mathrm{O}_{2}$ mixtures diluted in argon behind shock waves and showed that the concentration of electrons and ions arising from the ionization of the natural sodium impurities in a shock-heated gas changes considerably in the presence of carbon nanoparticles. In [7], we investigated the charging of nanoparticles formed during the pyrolysis of $\mathrm{CCl}_{4}$ mixture with argon behind shock waves and showed that the presence of chlorine atoms in the mixture leads to a considerable

(c) S.Y. BRONIN, A.V. EMELIANOV, A.V. EREMIN, A.G. KHRAPAK, E.Y. MIKHEYEVA, 2014

ISSN 2071-0194. Ukr. J. Phys. 2014. Vol. 59, No. 4 decrease in the concentration of electrons in the gasparticles system and to decrease in the concentration of charged nanoparticles. In [6,7], the kinetic model describing the electron trapping by carbon nanoparticles was proposed, which agrees well with the experimental results obtained. In this paper, the results of investigation of the charging of carbon nanoparticles formed during the pyrolysis of hydrocarbon mixtures with argon behind shock waves are presented, and the comparison of these results with previous ones for the hydrogen-free carbon-bearing mixtures is carried out.

\section{Experimental Setup}

The experiments were performed in a shock tube with a 50-mm inner diameter and a 4.5-m long driven section. The experimental setup was described in detail in [5-7]. Particle charging was studied in the mixtures initially containing of $0.5-1 \% \mathrm{C}_{6} \mathrm{H}_{6}$ in Ar. The temperatures $T_{5}$ and the pressures $P_{5}$ behind the reflected shock wave were varied in the range of 1900-3200 K and 2-8 bar. The process of propagation of the incident and reflected shock waves and 
the following growth of carbon nanoparticles was observed by means of laser extinction measurements at $633 \mathrm{~nm}$. The time resolution of these measurements was $(1-2) \times 10^{-6}$ s. For measurements of the concentrations of free electrons and ions, the shock tube was equipped with two sensitive electric Langmuir probes. The diameter of each probe was $6 \mathrm{~mm}$, and the electric voltage on the probes could be changed in the $\pm 50 \mathrm{~V}$ range. The calibration experiments were performed in pure argon and described in detail in [6].

The emission-absorption spectroscopy technique in the visible range of the spectrum was applied to the time-resolved temperature measurements of the nanoparticles formed during the pyrolysis. This technique is based on the simultaneous detection of emission and absorption from the identical volumes at the same wavelength. Taking Lambert-Beer's and Kirchhoff's laws into account, one can get the following expression for the temperature:

$T(t)=\frac{h c}{\lambda k}\left\{\ln \left[1+\left(\exp \left(\frac{h c}{\lambda k T_{0}}\right)-1\right) \times\right.\right.$

$\left.\left.\times\left(1-\frac{I_{a}(t)-I_{0}}{I_{e}(t)}\right)\right]\right\}^{-1}$.

Here, $I_{e}(\mathrm{t})$ and $I_{a}(\mathrm{t})$ are the time-resolved intensities of emission and absorption + emission, respectively, $h$ is the Planck constant, $c$ is the speed of light, $k$ is the Boltzmann constant, $\lambda$ is a diagnostic wavelength, $T_{0}$ is the brightness temperature of the reference source, and $I_{0}$ is the initial intensity of radiation of the reference source. A tungsten ribbon lamp was used as a reference source for the absorption channel. The wavelength of $589 \mathrm{~nm}$ corresponding to the sodium D-line was chosen in order to measure the gas temperature before the condensed phase appearance.

The time-resolved laser-induced incandescence (LII) technique was applied to the particle sizing. The LII is widely used for soot measurements in flames [11]. The technique is based on the measurement of the decay of thermal radiation from the particles preliminarily heated by a laser pulse. In our study, the wavelength of a heating-up Nd:YAG laser was $1064 \mathrm{~nm}$. The incandescence signals from particles were registered at wavelengths of 488 and $760 \mathrm{~nm}$ by two fast photomultipliers and recorded by a $500 \mathrm{MHz}$ scope. The LII model used and the method of evaluation of the mean particle size and the optical properties are described in detail in [12].
The measurements of the nanoparticle charge by electric probes, as well as their temperature by emission-absorption spectroscopy, and the size by LII, were performed simultaneously.

\section{Kinetics Modeling}

The theoretical analysis of the probe measurement results requires the study of (a) the ionization kinetics of the sodium impurities, (b) the formation of soot particles, and (c) the charging of soot particles upon the recombination of charged plasma components at their surfaces. The plasma formation behind the reflected shock wave front in the absence of $\mathrm{C}_{6} \mathrm{H}_{6}$ was calculated with regard for the following processes:

$$
\begin{aligned}
& \mathrm{NaCl}+\mathrm{Ar}+4.26 \mathrm{eV} \rightarrow \mathrm{Na}+\mathrm{Cl}+\mathrm{Ar}, \\
& \mathrm{Na}+\mathrm{Ar}+2.1 \mathrm{eV} \rightarrow \mathrm{Na}^{*}+\mathrm{Ar}, \\
& \mathrm{Na}^{*}+\mathrm{Ar}+3.04 \mathrm{eV} \rightarrow \mathrm{Na}^{+}+\mathrm{e}+\mathrm{Ar}, \\
& \mathrm{NaCl}+\mathrm{Ar}+5.8 \mathrm{eV} \rightarrow \mathrm{Na}^{+}+\mathrm{Cl}^{-}+\mathrm{Ar}, \\
& \mathrm{Cl}^{-}+\mathrm{Ar}+3.61 \mathrm{eV} \rightarrow \mathrm{Cl}+\mathrm{e}+\mathrm{Ar}
\end{aligned}
$$

Here $\mathrm{Na}^{*}$ designates the intermediate electronically excited $3 p$ level. The equilibrium parameters corresponding to the conditions behind the reflected shock wave were taken as the initial conditions. The rate constant values recommended in [13] and extrapolated to the temperature range of 1500-3500 K (see also [6]) were taken as the rate constants for the reactions involving sodium. In the experiments with $\mathrm{C}_{6} \mathrm{H}_{6}$, the temperature of the gas mixture differs from $T_{5}$ by the heat consumption due to the benzene decomposition and the following heat release at the carbon condensation [14]. For simplicity of the subsequent analysis, it is assumed that the growth of soot particles is described by the scheme involving only the atomic carbon:

$\mathrm{C}_{N}+\mathrm{C} \rightarrow \mathrm{C}_{N+1}$,

where $N$ is the number of carbon atoms in a particle. The rate constant of this reaction was obtained from that given in [15] for $N=45$ under the assumption that it is proportional to the particle cross-section, which, in turn, is proportional to $N^{2 / 3}$ :

$a(N)=3.5 \times 10^{-11} T^{1 / 2}(N / 45)^{2 / 3} \mathrm{~cm}^{3} \mathrm{~s}^{-1}$.

It is also assumed that the concentration $n_{d}$ of soot particles is constant and equal to the concentration of 
initial condensation centers, the size of all soot particles being considered to be identical at any time. In calculations, their concentrations varied within $10^{11_{-}}$ $10^{12} \mathrm{~cm}^{-3}$. In fact, at any time, there is some size distribution of soot particles, and the total concentration of soot particles can vary with time. The formation of soot particles is accompanied by the growth of the enthalpy due to the heat released during the condensation. The quantitative account for the heat was carried out, based on temperature measurements. The soot particles formed under the conditions of this experiment influence the ionization equilibrium in plasma, since an additional mechanism of ion and electron recombination occurs at the surface of particles. Under these conditions, the flow of charged plasma components is proportional to the concentration of these components. The recombination of plasma components at the soot particle surface is taken into account by addition of the corresponding summands to the kinetic equations

$\left\{\frac{d n_{e}}{d t}\right\}_{\mathrm{rec}}=-\frac{n_{e}}{\tau_{e}}, \quad\left\{\frac{d n_{\mathrm{Na}^{+}}}{d t}\right\}_{\mathrm{rec}}=-\frac{n_{\mathrm{Na}^{+}}}{\tau_{\mathrm{Na}}}$,

where, $\tau_{\alpha}$ is an analog of the characteristic time of bulk recombination, which characterizes the loss of charged particles recombining at the soot particle surface. If the particle has no charge, the $\tau_{\alpha}$ values are determined by the charged particle mobilities and the ratio between the soot particle size and the free path length $l_{\alpha}$ of charged components. For the conditions under consideration, $l_{e} \approx 0.1 \mu \mathrm{m}$ and $l_{\mathrm{Na}} \approx l_{\mathrm{Cl}} \approx$ $\approx 0.01 \mu \mathrm{m}$, and all these lengths are much less than the Debye layer thickness and comparable with the typical size of soot particles $a \approx 0.015 \mu \mathrm{m}$. In this case, the total transit time of a charged plasma particle to the soot particle surface is composed from the transit times through the Knudsen layer and through the external diffusion part of the Debye layer [8,9]:

$\tau_{\alpha}=\frac{1}{n_{d} \nu_{T \alpha} a^{2}}\left(\frac{1}{1 \sqrt{2 \pi}}+\frac{1}{\left.4 \pi\left(1+l_{\alpha}\right) / \alpha\right) l_{\alpha} / \alpha}\right)$,

where $\nu_{T}$ is the thermal velocity of the $\alpha$ component. The presence of a charge creates the potential barrier $\Delta \phi=e^{2} Z / a$ ( $Z$ is the particle charge, in $e$ ) for the recombination on the particle of the same sign. Under the considered conditions $Z<0$, and the charge effect is taken into account by the factor $\exp (Z e \Delta \phi / k T)$ on the right-hand side of Eqs. (1) corresponding to

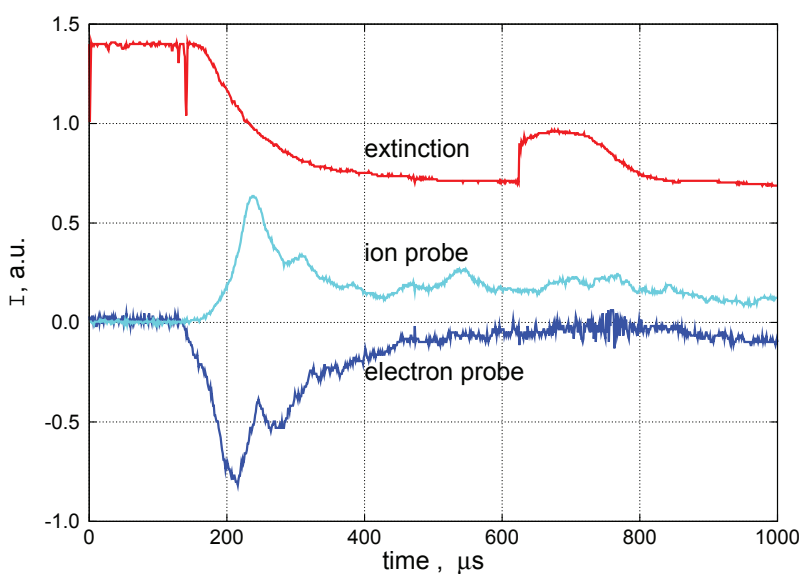

Fig. 1. Example of the time profile of the laser extinction and signals from the positive and negative probes. Mixture of $1 \%$ $\mathrm{C}_{6} \mathrm{H}_{6}$ in $\mathrm{Ar}$ at $T_{5}=2120 \mathrm{~K}\left(T_{\text {eq }}=1950 \mathrm{~K}\right), P_{5}=3.6 \mathrm{bar}$; particle size is $8 \mathrm{~nm}$

electrons and chlorine ions. For the charging kinetics of soot particles, we get

$n_{d} \frac{d Z}{d t}=\frac{n_{\mathrm{Na}^{+}}}{\tau_{\mathrm{Na}}}-\left(\frac{n_{\mathrm{Cl}^{-}}}{\tau_{\mathrm{Cl}}}+\frac{n_{e}}{\tau_{e}}\right) \exp \left(\frac{Z e^{2}}{\alpha k T}\right)$.

Here, it was taken into account that the $Z$ value in the calculations was everywhere small in absolute magnitude, which made it unnecessary to take into account its effect on the positive plasma particle flows. The kinetic processes given above are described by a system of seven equations for the concentrations of different plasma components, as well as for the soot particle sizes and charges.

\section{Experimental Results and Discussion}

Figure 1 shows the time profiles of the laser extinction signals and signals from the positive and negative probes for a mixture of $1 \% \mathrm{C}_{6} \mathrm{H}_{6}$ in $\mathrm{Ar}$ at $T_{5}=2120 \mathrm{~K}, P_{5}=3.6$ bar. One can conclude from the form of the signals that the particles are formed within $t \sim 300 \mu \mathrm{s}$ and are stable throughout the experiment. The time of the peak signal achievement for the electron and ion probes was $\sim 100 \mu \mathrm{s}$, which suggests the formation of a charge on the growing particles. However, in contrast to the experiments in pure Ar [6], the sharp maximum in both signals is followed by a zone of signal decrease, the duration of which is about $200 \mu \mathrm{s}$. The measurements showed that the peak signal on the ion probe is several times 

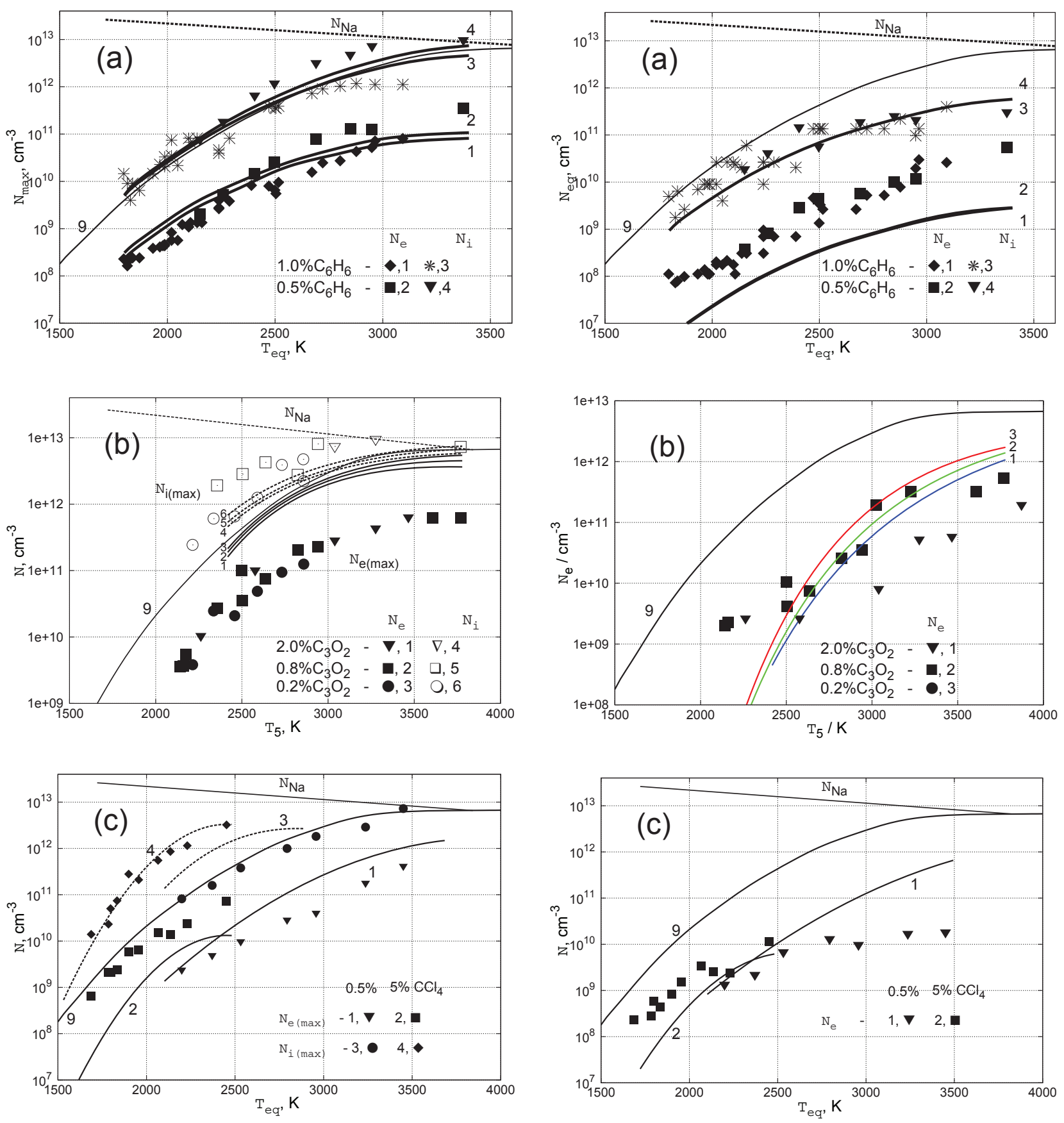

Fig. 2. Comparison of the measured and calculated maximum concentrations of electrons $N_{e(\max )}$ and ions $N_{i(\max )}$ in different mixtures: $\mathrm{C}_{6} \mathrm{H}_{6}-(a), \mathrm{C}_{3} \mathrm{O}_{2}-(b), \mathrm{CCl}_{4}-(c)$ in argon. The solid line (9) is the equilibrium electron and ion concentrations in argon with the natural sodium admixture. The upper dashed line shows the total Na concentration of $2 \times 10^{-5} \%$ in $\mathrm{Ar}$

Fig. 3. Comparison of the measured and calculated final electrons $N_{e(e q)}$ and ions $N_{i(\text { eq })}$ concentrations in different mixtures: $\mathrm{C}_{6} \mathrm{H}_{6}-(a), \mathrm{C}_{3} \mathrm{O}_{2}-(b), \mathrm{CCl}_{4}-(c)$ in argon. The solid line (9) is the equilibrium electron and ion concentrations in argon with the natural sodium admixture. The upper dashed line shows the total Na concentration of $2 \times 10^{-5} \%$ in $\mathrm{Ar}$ 
higher than the signal measured in pure argon, while the signal from the electron probe is several times lower than that in pure argon.

Figure 2, $a$ shows the comparison of the measured and calculated maximum concentrations of electrons $N_{e(\max )}$ and ions $N_{i(\max )}$ at different temperatures in mixtures of $0.5 \%$ and $1 \% \mathrm{C}_{6} \mathrm{H}_{6}$ in argon. The concentration of charged particles decreased by two times with increasing the concentration of $\mathrm{C}_{6} \mathrm{H}_{6}$ in the initial mixture from $0.5 \%$ to $1 \%$, which can be explained by increasing the concentration of carbon nanoparticles.

Figure 2, $b$ shows the comparison of the measured and calculated maximum concentrations of electrons $N_{e(\max )}$ and ions $N_{i(\max )}$ at different temperatures in mixtures of $0.2 \%, 0.8 \%$, and $2 \% \mathrm{C}_{3} \mathrm{O}_{2}$ in argon. A considerable deviation of all concentrations from the equilibrium curve (curve 9 in Fig. $2, b$ ) is clearly observed. The concentration of charged particles is almost independent of the concentration of $\mathrm{C}_{3} \mathrm{O}_{2}$ in the initial mixture.

Figure 2, $c$ shows the comparison of the measured and calculated maximum concentrations of electrons $N_{e(\max )}$ and ions $N_{i(\max )}$ at different temperatures in mixtures of $0.5 \%$ and $5 \% \mathrm{CCl}_{4}$ in argon. The concentration of charged particles increased by an order of magnitude with increasing the concentration of $\mathrm{CCl}_{4}$ in the initial mixture from $0.5 \%$ to $5 \%$, which can be explained by the increase in the concentration of carbon nanoparticles. Although the chlorine concentration also increases, the effect of chlorine becomes less noticeable.

Figure 3 shows the comparison between the measured and calculated values of the final electron concentration $N_{e(\text { eq })}$, which were measured at different concentrations of particles in mixtures of $\mathrm{C}_{6} \mathrm{H}_{6}, \mathrm{C}_{3} \mathrm{O}_{2}$ and $\mathrm{CCl}_{4}$ in argon. All these values are several orders of magnitude less than the equilibrium electron concentration in the absence of particles. The divergence between the calculated and measured values is caused by the imperfection of the kinetic model for the formation of soot particles, since there is no enough information on the rate constants for the decomposition of $\mathrm{C}_{6} \mathrm{H}_{6}$ and the formation of soot particles.

The proposed modeling of the charging of particles in the process of their formation presents the satisfactory agreement of simulations with the experimental data. In this model, the particle size determined in the experiments has been used, but, at the tem- peratures above $2800 \mathrm{~K}$, the model must involve the emergence of hydrocarbon radicals and their thermal ionization.

The comparison with the previous results $[6,7]$ on the charging of soot nanoparticles by the pyrolysis of $\mathrm{C}_{3} \mathrm{O}_{2}$ shows that, in $\mathrm{C}_{3} \mathrm{O}_{2}$, the difference between the equilibrium electron concentration in the absence of particles and the final electron concentration decreases with increasing the temperature. At the same time, in the presence of particles formed at the pyrolysis of $\mathrm{CCl}_{4}$, the difference between the measured final electron concentration and the equilibrium one increases with the temperature, which, as was shown in [7], is due to the presence of chlorine atoms trapping free electrons. In the presence of particles formed at the pyrolysis of $\mathrm{C}_{6} \mathrm{H}_{6}$, the difference between the measured final electron concentration and the equilibrium ones remains nearly constant.

\section{Conclusions}

In the presence of condensed carbon nanoparticles produced during the pyrolysis of $\mathrm{C}_{6} \mathrm{H}_{6}, \mathrm{C}_{3} \mathrm{O}_{2}$, and $\mathrm{CCl}_{4}$ for about 50 microseconds after the arrival of the front of the shock wave, the free electron concentration is reduced by two orders of magnitude, while the concentration of positive ions changes slightly.

The equilibrium concentration of free electrons in the presence of particles in all mixtures is much smaller than in the same gas without particles.

In $\mathrm{C}_{3} \mathrm{O}_{2}$, the difference between the equilibrium electron concentration in the absence of particles and the final electron concentration decreases, as the temperature increases. In $\mathrm{C}_{6} \mathrm{H}_{6}$, this difference remains essentially constant. In $\mathrm{CCl}_{4}$, this difference increases with the temperature, which is due to the presence of chlorine atoms trapping free electrons.

The obtained results of modeling of the charging of particles in the process of their formation present the satisfactory agreement with the experimental data. In this model, the experimentally determinated particle size has been used, but, at the temperatures above $2800 \mathrm{~K}$, the model must take the emergence of hydrocarbon radicals and their thermal ionization into account.

The support of this study by RFBR (Projects No.11-08-00873-a and 13-02-01099-a) is gratefully acknowledged. 
1. J. Deppe, A. Emelianov, A. Eremin, H. Jander, H.Gg. Wagner, and I. Zaslonko, Proc. Combust. Inst. 28, 2515 (2000).

2. A. Emelianov, A. Eremin, H. Jander, and H.Gg. Wagner, Proc. Combust. Inst. 29, 2351 (2002).

3. A. Emelianov, A. Eremin, H. Jander, A. Makeich, P. Roth, R. Starke, and H.Gg. Wagner, Proc. Combust. Inst. 30, 1433 (2004).

4. A. Emelianov, A. Eremin, A. Makeich, H. Jander, H.Gg. Wagner, R. Starke, and C. Schulz, Proc. Combust. Inst. 31, 649 (2007).

5. A. Emelianov, A. Eremin, and H. Jander, Proc. Combust. Inst. 32, 721 (2009).

6. S. Bronin, A. Emelianov, A. Eremin and A. Khrapak, High Temperature 49, 349 (2011).

7. S. Bronin, A. Emelianov, A. Eremin and A. Khrapak, High Temperature 50, 687 (2012).

8. V. Fortov, A. Khrapak, S. Khrapak, V. Molotkov, and O. Petrov, Physics-Uspekhi 47, 447 (2004).

9. V.N. Tsytovich, G.E. Morfill, and H. Thomas, Plasma Phys. Rep. 28, 623 (2002).

10. B.M. Smirnov, Physics-Uspekhi 43, 453 (2000).

11. P. Desgroux, X. Mercier, and K. Thomson, Proc. Combust. Inst. 34, 1713 (2013).

12. A. Eremin, E. Gurentsov, E. Popova, and K. Priemchenko, Appl. Phys. B 104, 285 (2011).

13. K.-P. Schneider and C. Park, Phys. Fluids 18, 969 (1975).
14. A. Eremin, E. Gurentsov, and E. Mikheyeva, in 6-th European Combustion Meeting, June 25-28, 2013, P1-50 (Lund, Sweden, 2013).

15. A. Krestinin, A. Moravskij, and P. Tesner, Chem. Phys. 17, 70 (1998).

Received 28.11.13

С.Я.Бронін, А.В. Ємельянов,

А.В. Єръомін, А.Г. Храпак, Е.Ю. Міхеєва

ЕКСПЕРИМЕНТАЛЬНЕ ТА ТЕОРЕТИЧНЕ

ДОСЛІДЖЕННЯ ЗАРЯДКИ ВУГЛЕЦЕВИХ

НАНОЧАСТИНОК В УДАРНО-ЗІГРІТІЙ ПЛАЗМІ

ПРИ ПІРОЛІЗІ ВУГЛЕЦЕВОВМІСНИХ МОЛЕКУЛ

$\mathrm{P}$ е $з$ ю м е

У роботі наведено дослідження кінетики зарядки вуглецевих наночастинок, що утворюються при піролізі вуглецевовмісних молекул за ударними хвилями. Представлено результати експериментів і комп'ютерного моделювання процесу зарядки вуглецевих наночастинок, що формуються в процесі піролізу $\mathrm{C}_{6} \mathrm{H}_{6}$ в ударно-нагрітій плазмі. Проведено порівняння процесу зарядки наночастинок, що утворюються при піролізі $\mathrm{C}_{3} \mathrm{O}_{2}, \mathrm{CCl}_{4}$ i $\mathrm{C}_{6} \mathrm{H}_{6}$. Показано відмінність процесу зарядки наночастинок, які утворюються з безводневовмісних молекул щодо вуглецевоводневих. 